\title{
VISIBILIDADE DE DOCUMENTOS EM ACESSO ABERTO: NECESSIDADE DE EDUCAÇÃO DO USUÁRIO
}

\author{
Jorge Santa Anna
}

\section{RESUMO}

Discute aspectos relacionados à disponibilização de documentos digitais e sua utilização pelos usuários em espaço aberto. Para tanto, contextualiza a gênese e desenvolvimento do ciberespaço na sociedade moderna. Apresenta o contexto de desenvolvimento $e$ as funcionalidades do acesso aberto. Analisa o grau de conhecimento dos usuários a respeito do uso das tecnologias digitais e o acesso a documentos livres, de forma lícita. Expõe a importância e necessidade de adequações dos ambientes digitais, face aos obstáculos enfrentados pelos usuários, bem como a capacitação deles na utilização de documentos disponibilizados em espaço aberto. Metodologicamente, foram utilizados procedimentos de pesquisa bibliográfica, documental e estudo em campo, através de entrevistas a um grupo de pesquisadores e profissionais. Por fim, concluiu-se que é preciso estabelecer políticas de acesso a esses ambientes, bem como a divulgação de como utilizar os documentos sem impactar com problemas de direitos autorais. Também se infere a necessidade de capacitar o usuário da informação eletrônica, tendo em vista sua adequação aos limites impostos pelo ambiente virtual.

Palavras-chaves: Novas tecnologias. Acesso aberto. Direitos autorais. Políticas de acesso. Capacitação. 


\section{ABSTRACT}

Discusses aspects related to the availability of digital documents and its use by users in open space. To do so, contextualizes the genesis and development of the cyberspace in modern society. Presents the context of development and the functionalities of open access. Analyzes the degree of users' knowledge about the use of digital technologies and access to free documents, lawfully. Exposes the importance and need of adjustments of digital environments, due to the obstacles faced by users, as well as enabling them in the use of documents available in open space. Methodologically, were used procedures of bibliographical and documentary research, and field study by interviewing a group of researchers and professionals. At last, it was concluded that we need to establish policies of access to these environments, as well as the disclosure of how to use the documents without impacting with copyright issues. Also infers the need to empower the user of electronic information, in view of their adequacy to limits imposed by the virtual environment.

Keywords: New technologies. Open access. Copyright. Access policies. Training.

\section{INTRODUÇÃO}

O desenvolvimento tecnológico e os paradigmas instituídos pela sociedade contemporânea favorecem a concepção de ideias inéditas a respeito da disseminação da informação e seu uso pela sociedade. Essa ocorrência é fruto das novas necessidades impostas pelo espaço social, pautado na informação como insumo básico no desenvolvimento pessoal, cultural e econômico de uma nação.

Essa realidade viabiliza o fortalecimento de práticas em prol do acesso democrático à imensa onda de informações que permeiam o atual contexto. Assim, inúmeras questões são levantadas a respeito do movimento do acesso aberto, sobretudo, com o desenvolvimento da internet, que favoreceu o surgimento de um espaço interativo de acesso e compartilhamento de informações, tornando mais fácil o processo de comunicação científica.

Nesse contexto, tendo como base a pesquisa de Weitzel (2006), entende-se que esse movimento cria estruturas viáveis que permitem o acesso irrestrito à produção científica legítima, alterando não somente o processo de aquisição de informação científica, mas também a sua produção, disseminação e uso.

O movimento do acesso aberto possui uma proposta favorável à democratização do conhecimento na sociedade, garantindo, de modo geral, a concretização da cidadania, efetivando o cumprimento de direitos e deveres. No entanto, muitos problemas vêm à tona sobre a disponibilização de informações eletrônicas, problemas esses relacionados, sobremaneira, a uma nova conjuntura refletida na indústria editorial. 
Está evidente que a consolidação do acesso aberto impacta nos processos e fluxos que permeiam a comunicação científica, favorecendo a consolidação de novas ambiências. Assim, a informação passa a ser transferida por meio de diferentes tipos de canais, envolvendo fluxos variados, por conseguinte, redefinindo novos papéis atribuídos a todos os profissionais que atuam na produção científica.

O estudo de Mueller (2006) enfatiza que o movimento para o acesso aberto ao conhecimento científico pode ser considerado como o fato mais interessante e talvez importante de nossa época no que se refere à comunicação científica. Ao mesmo tempo, este movimento representa enorme desafio para a comunidade científica, à medida que, quanto mais amplo o seu sucesso, mais radical será a mudança provocada no sistema tradicional e profundamente arraigado de comunicação do conhecimento científico.

No entendimento de Johnson (2002 apud LEITE, 2009), na conjuntura atual, a indústria editorial está sendo redefinida. Isso porque cresce claramente o papel de modelos alternativos de comunicação científica, tais como repositórios institucionais e bases de dados, ao quebrarem monopólios de editores e aumentarem a atenção e ciência de pesquisadores sobre a produção intelectual das universidades e institutos de pesquisa.

Sendo assim, este estudo atrela-se à temática do acesso aberto, enfatizando questões relacionadas à ampliação da sua visibilidade, garantindo a legitimidade dessas práticas. A questão norteadora na qual se apoia o referido estudo visa a encontrar respostas a respeito das práticas e percepções de usuários envolvidos no processo de comunicação científica quanto aos desafios impostos pelo ciberespaço.

Por decorrência, este artigo objetiva discutir aspectos relacionados à disponibilização de documentos digitais e sua utilização pelos usuários em espaço aberto. Para tanto, o estudo visa a contextualizar a gênese e desenvolvimento do ciberespaço na sociedade moderna; apresentar o contexto de desenvolvimento e as funcionalidades do acesso aberto; analisar o grau de conhecimento dos usuários a respeito do uso das tecnologias digitais e o acesso a documentos livres, de forma lícita. Além disso, expor a importância e necessidade de adequações dos ambientes digitais, face aos obstáculos enfrentados pelos usuários, bem como à sua capacitação para uso de documentos disponibilizados em espaço aberto.

Com base nessa realidade, o estudo torna-se pertinente, uma vez que a informação disponibilizada em novos artefatos tecnológicos desencadeia o surgimento de instrumentos até então não utilizados e adequação de técnicas e metodologias, assim como provoca também a necessidade de controle das condutas que precisam ser gerenciadas a fim de garantir o uso legal da informação eletrônica.

Metodologicamente, foram utilizados procedimentos de pesquisa bibliográfica, documental e estudo de campo, através de entrevistas a um grupo de pesquisadores, com vistas a coletar dados a respeito das práticas e percepções desses sujeitos no contexto do acesso aberto. 
O estudo bibliográfico foi sustentado por autores renomados da área da Ciência da Informação, utilizando-se como materiais de pesquisa, livros e artigos por eles publicados. Para a análise documental, utilizaram-se fontes jurídicas, como Constituição Federal e a Lei de Direitos Autorais (Lei 9610). Já o estudo de campo teve como espaço de investigação, uma universidade federal, tendo como sujeitos de pesquisa, indivíduos vinculados a essa instituição: três pesquisadores, um profissional bibliotecário e um editor de revista eletrônica.

A técnica para coleta de dados foi a entrevista aplicada a esses sujeitos, de forma individualizada, sendo as informações fornecidas devidamente anotadas e gravadas, a fim de facilitar o processo de apresentação e interpretação dos dados coletados.

\section{DIÁLOGO COM ALGUNS TEÓRICOS}

A utilização da internet desencadeou inúmeras transformações que afetaram a sociedade em todas as suas dimensões, interferindo no comportamento de indivíduos e instituições. No âmbito da indústria da informação, a utilização de novos canais de transferência desencadeou diferentes formas de compartilhamento, proporcionando novas ambiências no processo de comunicação científica.

Se antes, as pesquisas eram compartilhadas através de processos tradicionais, como o uso de cartas, acarretando morosidade na produção de conhecimentos, na atualidade, o uso dos recursos fornecidos pela internettorna esse processo cada dia mais eficaz, podendo a informação ser socializada sem considerar barreiras geográficas (MUELLER, 2000).

A expansão da internet provocou mudanças comportamentais, havendo a necessidade de redefinição de muitos processos de trabalho, caracterizando a sociedade atual como um espaço integrado em redes, em que as informações são compartilhadas instantaneamente e em várias localidades (CASTELLS, 2007). Desse modo, desperta-se a formação de um novo espaço social, o ciberespaço, caracterizado como

[...] um novo espaço de interação humana que já tem uma importância enorme, sobretudo no plano econômico e científico e, certamente, essa importância vai ampliar-se e vai estender-se a vários outros campos [...]. O espaço cibernético é a instauração de uma rede de todas as memórias informatizadas e de todos os computadores (LÉVY, 1999, p. 29).

Nessa nova realidade, propaga-se a Teoria do Rizoma, ao defender que as instituições pertencentes à sociedade contemporânea, inseridas em um contexto de globalização, tendo auxílio das novas tecnologias, estão atreladas umas às outras, compartilhando informações em um processo contínuo, sem delimitação de início e fim (DELEUZE; GUATARY, 1995). 
O aumento da produção bibliográfica foi condicionado, em grande parte, pelo avanço das novas tecnologias e com o uso da internet, os quais viabilizaram a criação de novas fontes de informação, bem como a transmissão da informação. De modo especial, os periódicos científicos têm sido uma das fontes que mais cresceu nas últimas décadas, representando um importante meio de comunicação a ser utilizado por autores, publicadores, bibliotecários e usuários (PACKER, 2005).

O mesmo autor defende que, a disponibilização do periódico em espaço digital desencadeou as primeiras resistências ligadas à defesa do papel como suporte de registro e publicação, que foram paulatinamente superadas devido às extraordinárias facilidades, potencialidades e conveniências oferecidas pelo acesso online aos artigos e outros textos.

Consolidam-se, na contemporaneidade, novos desafios, tanto para pesquisadores, autores e consumidores de informação, quanto para os profissionais e as instituições que atuam no controle, armazenamento e disponibilização das fontes eletrônicas.

Especificamente no contexto das bibliotecas e instituições de pesquisa, essas unidades vêm se constituindo como um espaço destinado a fornecer o acesso a todo tipo de fonte de informação a qualquer usuário, desconsiderando as limitações de tempo e espaço. Esse processo de interação dessas unidades com seus públicos, sem medir as fronteiras geográficas, somente é conseguido com o apoio das novas tecnologias da informação e comunicação (TIC) (SANTA ANNA, 2013).

Vê-se que as novas formas de disponibilização da informação, favorecendo diferentes mecanismos de comunicação, constituem um dos fatores mais interferentes na indústria da informação. Isso provoca, simultaneamente, inúmeras vantagens, sobretudo no que se refere à ampliação do acesso, como também pode representar obstáculos, face às novas estruturas tecnológicas e as formas e condições de seu uso.

Dentre os vários fatores que interferem no processo de comunicação científica, o movimento para o acesso aberto ao conhecimento científico vem sendo estudado com grande frequência, devido a sua importância (MUELLER, 2006). Segundo Oliveira e Gomes (2013), esse movimento é constituído por um conjunto de práticas diferenciadas da tradicional maneira de comunicar o conhecimento científico, no que se refere ao acesso às publicações periódicas condicionadas ao pagamento de caras assinaturas. $O$ direito autoral tem se mostrado um dos principais entraves para a expansão do movimento de acesso aberto.

Assim, o acesso aberto, nesse contexto, significa

[...] a disponibilização livre pública na Internet, de forma a permitir a qualquer usuário a leitura, download, cópia, distribuição, impressão, busca ou criação de links para os textos completos dos artigos, bem como capturá-los para indexação ou utilizá-los para qualquer outro propósito legal [...] (LEITE, 2009, p. 15, grifo nosso). 
Mueller (2006, p. 27) esclarece que, embora a proposta do acesso aberto vise a consolidar a disseminação do conhecimento, viabilizando sua produção, face às facilidades de compartilhamento, ele provoca mudanças impactantes. Segundo a mesma autora, a chegada do periódico científico eletrônico, na década de 90, despertou "[...] esperanças, em muitos pesquisadores, de uma mudança radical no sistema tradicional de comunicação científica".

No decorrer dos tempos, o movimento do acesso aberto preocupa pesquisadores do mundo todo, sendo motivo de discussão entre especialistas envolvidos no mercado editorial, além de ser objeto de discussão em eventos de diferentes áreas. Nos anos de 2000 a 2003 foram realizados, nas cidades de Budapeste, Bethesda e Berlim, três importantes eventos em prol do acesso aberto às publicações científicas (OLIVEIRA; GOMES, 2013).

De modo geral, esses eventos resultaram na elaboração de três declarações que, posteriormente, constituiriam relevantes manifestações em favor do acesso aberto às publicações científicas no mundo. Os referidos eventos convocaram autores, associações científicas, editores, universidades e bibliotecas a trabalharem na remoção das barreiras que impedem o acesso livre à literatura científica (OLIVEIRA; GOMES, 2013).

Como resultado da Declaração de Budapeste, sendo consolidado, posteriormente, pela Declaração de Berlim, o movimento de acesso aberto estabeleceu duas importantes estratégias, definidas como linha verde e dourada. A primeira referese "[...] ao depósito de trabalhos científicos que tenham sido publicados em revistas de acesso restrito em repositórios temáticos ou institucionais [...]" (OLIVEIRA; GOMES, 2013, p. 2). Segundo os mesmos autores, essa estratégia também pode ser chamada de autoarquivamento, pois é realizada pelos próprios autores dos artigos. Já a segunda diz respeito "[...] aos trabalhos científicos publicados em revistas que aderiram ao Movimento de Acesso Aberto ou Open Access (OA)" (OLIVEIRA; GOMES, 2013, p. 2).

No caso específico da disponibilização de periódicos científicos em espaço aberto, segundo Ortellado (2008 apud OLIVEIRA; GOMES, 2013), destaca-se o grande obstáculo para a legitimação desse movimento, pois, o processo editorial realizado muitas vezes por instituições privadas é comprometido, devido à democratização dos documentos antes disponibilizados de forma comercial.

A respeito da importância do acesso aberto a informações científicas e em meio às diversas discussões existentes, Kuramoto (2009, p. 7) disserta que

O acesso à informação científica tornou-se, em consequência das barreiras existentes, um dos grandes desafios no mundo de hoje. Uma dessas barreiras, o custo crescente da assinatura dos principais periódicos científicos, provocou a chamada crise dos periódicos científicos. Para superar essa crise, pesquisadores de diversas partes do globo terrestre se reuniram e deram início a um grande movimento global em direção ao acesso aberto à informação científica. 
Os defensores do movimento de acesso aberto partem do princípio de que se deve priorizar a oferta gratuita de informações, concretizando a democratização do conhecimento, sem limitações. Defende-se a eliminação de quaisquer barreiras financeiras, legais ou técnicas, além daquelas próprias do acesso à internet. A única restrição à reprodução e distribuição e a única função do copyright nesse contexto devem ser o controle dos autores sobre a integridade de sua obra e o direito de serem adequadamente reconhecidos e citados (BUDAPEST OPEN ACCESS INITIATIVE, 2001 apud LEITE, 2009).

Se por um lado, o movimento do acesso aberto viabiliza o processo de disseminação da informação, tornando o conhecimento mais acessível, em contrapartida, surge a necessidade de se desenvolver mecanismos que garantam o respeito aos responsáveis pela criação e divulgação da informação, atendendo a princípios legalmente instituídos por legislações específicas (FREITAS; MAIA; LEITE, 2011).

É perceptível que esses processos são complexos, o que requer o estabelecimento de políticas voltadas para gerenciar e controlar com integridade e legitimidade as informações disponibilizadas. A pesquisa de Ferrari e Pires (2014) sinaliza essa necessidade, enfatizando haver prioridade na elaboração de diretrizes que promovam a normatização, tendo em vista, o uso adequado do compartilhamento de informações, sem provocar infrações à legislação em vigor.

As complexidades advindas com o uso e expansão acentuada da internet condicionam a elaboração de parâmetros que garantam a utilização legitimada do ciberespaço, tornando-o um ambiente lícito e influenciador na construção de conhecimento (SANTA ANNA, 2013).

Por conseguinte, instituir regras constitui um trabalho cauteloso que requer pesquisas prévias, a fim de garantir maior consistência e integridade nas normas, instrumentos e estratégias de controle. Assim, antes de qualquer ação, é preciso entender o trabalho de organização da informação e as complexidades do ciberespaço, com vistas a construir uma cultura colaborativa, levando em consideração inúmeras questões, sobretudo os interesses que envolvem as decisões do poder público (FERRARI; PIRES, 2014). 


\section{MATERIAIS E MÉTODOS}

A partir das questões refletidas por teóricos renomados da área de Biblioteconomia e Ciência da Informação, constata-se que, a utilização do ambiente virtual, especialmente com o desenvolvimento da internet, desencadeou muitos desafios que precisam ser superados a fim de garantir um uso efetivo da informação socializada pelos novos artefatos tecnológicos.

O movimento do acesso aberto, particularmente, evidencia problemas ainda mais elevados, pois além das questões complexas envolvidas no processo de organização e representação da informação eletrônica, remete ao estabelecimento de padrões normativos a fim de que a informação seja utilizada de forma lícita, sem provocar infrações contra a propriedade intelectual e editorial.

Partindo dessa contextualização, este estudo, realizado de forma preliminar, investiga em campo como um grupo de usuários de informação eletrônica, utiliza as informações disponibilizadas em ambiente digital, tendo em vista as complexidades envolvidas no movimento do acesso aberto.

Foram escolhidos como amostragem de pesquisa, três pesquisadores, sendo um aluno de graduação (entrevistado A), um aluno de mestrado (entrevistado B) e um aluno de doutorado (entrevistado $C$ ). Também compuseram a amostragem, dois profissionais envolvidos no mercado editorial da informação, sendo um bibliotecário atuante na organização de repositório de dados científicos (entrevistado D), e, por fim, um editor de revista eletrônica (entrevistado E). Na escolha desses sujeitos, levou-se em conta os principais indivíduos envolvidos no processo de pesquisa no âmbito universitário.

Os métodos de pesquisa empregados foram a pesquisa bibliográfica, a documental e estudo de campo. A pesquisa do tipo bibliográfica, segundo Gil (2010, p. 41), tem como objetivo [...] o aprimoramento de ideias ou descoberta de instituições. Seu planejamento é, portanto, bastante flexível, de modo que possibilite a consideração dos variados aspectos ao fato estudado [...]. Os materiais utilizados nesse método foram livros e artigos científicos publicados em revistas da área de Ciência da Informação.

Já a pesquisa documental, segundo o mesmo autor, emprega os materiais que ainda não sofreram tratamento de análise, ou que possam ainda ser reestruturados. As fontes utilizadas nesse método foram fontes de aspecto jurídico, como a Constituição Federal e a Lei de Direitos Autorais (Lei $n^{\circ}$ 9.610).

O estudo de campo foi realizado em uma instituição de ensino superior (universidade), tendo como sujeitos de pesquisa, três pesquisadores e dois profissionais atuantes na disponibilização de informação eletrônica, todos atuantes nessa instituição. O estudo de campo representa uma investigação, cujo objetivo é estudar a realidade dos indivíduos, grupos, comunidades e instituições (GIL, 2010). A técnica utilizada na coleta de dados foi a entrevista aberta, cujo objetivo é obter informações de interesse a uma investigação, onde o pesquisador formula perguntas orientadas, com um objetivo definido, frente a frente com o respondente e dentro de uma interação social (GIL, 1999). 
Quanto aos procedimentos para apresentação e análise dos dados, foi utilizada a descrição fiel das falas dos respondentes, analisando-as de acordo com as recomendações propostas pela literatura e por legislação vigente.

\section{APRESENTAÇÃO E ANÁLISE DE DADOS}

Primeiramente, os três sujeitos pesquisadores foram indagados a respeito de quais as fontes de informação mais utilizadas na condução de suas pesquisas, enfatizando, de modo especial, o uso de fontes eletrônicas, disponibilizadas na internet.

Os entrevistados foram unânimes ao destacarem que utilizam fontes impressas, recorrendo à biblioteca universitária da instituição, a fim de conseguir livros e artigos impressos, sobretudo quando precisam realizar estudos mais aprofundados. No entanto, a maioria dos materiais empregados são artigos publicados em revistas eletrônicas da área de interesse.

"[...] Utilizo a biblioteca poucas vezes, pois com a internet, consigo baixar artigos recentes, realizando a leitura, sem exigir grande esforço tanto na localização dos materiais quanto no momento de citar a fonte. Se a fonte me atende, compartilho com outros colegas de interesse [...]" (Entrevistado A).

"[...] A internet facilita meu trabalho, pois muita coisa já vem pronta, como as referências, bastando apenas copiar. [...] Mas, mesmo assim, ainda vou à biblioteca a procura de livros" (Entrevistado B).

"[...] Utilizo muito livro da biblioteca ou comprando-os [...] Os artigos consigo através de bases de dados confiáveis existentes no Portal de Periódicos da Capes, mesmo tendo algumas dificuldades para utilizá-lo, devido às muitas possibilidades oferecidas por esse espaço digital" [...] (Entrevistado C).

Nesse mesmo enfoque, os dois profissionais que trabalham na indústria editorial eletrônica foram investigados a respeito dos impactos que o uso das fontes eletrônicas vem desencadeando, sobretudo ao trabalho dos profissionais atuantes nesse mercado. De modo geral, esses sujeitos afirmaram que, a informação disponibilizada na internet facilita o processo de pesquisa dos usuários, no entanto, muitos problemas são originados devido ao uso indevido e/ou inadequado do espaço digital.

"[...] A criação da internet e seu uso na disponibilização de informações foi um dos maiores avanços [...]. Só que, para que a informação seja recuperada, precisa ser feito uma efetiva representação dos objetos digitais [...] Também é preciso capacitar o usuário para que aprenda a usar de modo adequado, de modo que explore todas as ferramentas disponíveis, bem como não infrinja leis de direitos autorais [...]" (Entrevistado D).

"A internet facilitou a vida das pessoas [...] Vejo que os profissionais que atuam nessa área devem disponibilizar a informação, preocupando-se em estabelecer estratégias que eduque os clientes ao uso legal da informação disponibilizada [...] Os editores, em especial, devem reformular suas práticas a fim de conquistar esse novo espaço de trabalho que está aflorando [...]" (Entrevistado E). 
Quanto a essa questão do novo ambiente existente para disponibilização e uso da informação científica, constata-se, com base na realidade estudada e com opiniões de autores da área, que esse espaço provoca inúmeros benefícios aos usuários da informação. Esses benefícios referem-se tanto aos processos de troca e busca de informações, quanto ao comportamento do usuário ao adquiri maior autonomia (OLIVEIRA; SANTOS; RODEGHERI, 2013).

Importante enfatizar que o advento da internet emerge como uma forma de efetivar a garantia dos direitos do cidadão no que se refere ao acesso à informação, tornando-a mais democrática. Essa garantia é fruto das possibilidades de manifestação e divulgação de ideias, através da livre circulação de conteúdo na web. No entanto, é necessário estabelecer medidas de controle, a fim de evitar conflitos no ciberespaço (OLIVEIRA; SANTOS; RODEGHERI, 2013).

Após essa discussão a respeito do uso das informações eletrônicas, os pesquisadores foram questionados a respeito do conhecimento que possuem em relação ao uso das tecnologias digitais e o acesso a documentos livres de forma lícita. Em linhas gerais, constatou-se que os três pesquisadores não conhecem muitas potencialidades oferecidas, assim como desconhecem as medidas impostas para garantia de direitos autorais e editoriais.

"[...] Localizo os artigos por meio da busca no Google, mesmo [...] Todo artigo que aparece, se for pertinente para o assunto que estou tratando, copio as informações e cito a fonte, sem preocupar-me com local que foi publicado ou outras considerações" [...] (Entrevistado A).

‘[...] Não gosto de procurar informações por meio dos catálogos das bases de dados, pois os acho confusos [...]. Vejo a internet como um espaço público para acessar e compartilhar informação. Sendo assim, não prendo-me a questões se a fonte tem algum direito reservado ou licenças específicas. $O$ importante é citar a fonte" [...] (Entrevistado B).

"[...] As ferramentas e estratégias para buscar a informação eletrônica são bacanas. Ajudam muito na localização, no entanto, muitas vezes, a informação existe na base de dados e não consegue ser localizada [...]". Eu penso que os direitos autorais são preservados, mas os direitos editoriais não tem como garanti-los, uma vez que a internet é um espaço democrático de compartilhamento [...]" (Entrevistado C).

A respeito do que fazem os profissionais no intuito de tornar as informações mais acessíveis para o usuário, viabilizando com mais intensidade a disseminação, os profissionais consideram como necessária a realização de um trabalho interdisciplinar, devendo considerar, a priori, as necessidades, dificuldades e costumes dos usuários, a fim de estabelecer melhores interfaces e formas de representação, assim como a construção de instrumentos normativos a fim de evitar o uso inadequado das informações existentes em acesso aberto. 
“[...] A construção do repositório dessa biblioteca reflete um trabalho árduo que não dá para ser feito isoladamente, mas requer a presença de vários profissionais [...] é preciso que seja valoriza a formação de uma comissão para tomar decisões a respeito das práticas de tratamento da informação, e principalmente fazer estudos de usuários a fim de conhecer o perfil da comunidade usuária (Entrevistado D).

"[...] Disponibilizamos serviço de sugestões no sítio da revista e com base nessas sugestões melhoramos a interface da revista [...] Temos o cuidado de disponibilizar os metadados da publicação, bem como Copyright, creative commons, dentre outras licenças e direitos relacionados à proteção intelectual [...] (Entrevistado E).

Com base nessas discussões, entende-se que, os profissionais da informação atuantes na construção de repositórios ou base de dados científicos devem seguir recomendações específicas da instituição à qual pertençam esses instrumentos. Essas recomendações "[...] constituem um conjunto de instruções que sistematizam processos que devem ser considerados no momento da elaboração e execução de um projeto de repositório institucional em universidades e institutos de pesquisa" (LEITE, 2009, p. 13).

A utilização de catálogos dinâmicos, permeados por diversas estratégias de busca e recuperação da informação, denominados de catálogo em linha de acesso público (OPAC), representou um grande avanço na localização de informações, diante da imensa quantidade de informação disponibilizada em ambientes eletrônicos. No entendimento de Oliveira (2008), a grande vantagem é a capacidade simultânea de recuperação da informação, além da variada possibilidade de pontos de acesso, por meio da introdução de hipertextos, viabilizando buscas não lineares e dinâmicas.

Quanto à preservação de direitos autorais e editoriais, analisando a legislação específica de direitos autorais, Lei $n^{\circ} 9610$, instituída no Brasil no ano de 1998, é preciso considerar que, mesmo estando em ambiente eletrônico, esses direitos devem ser respeitados. $\mathrm{O}$ art. $7^{\circ}$ dessa lei define que as obras intelectuais protegidas são as criações do espírito, expressas por qualquer meio ou fixadas em qualquer suporte, tangível ou intangível, conhecido ou que se invente no futuro, tais como: os textos de obras literárias, artísticas ou científicas; as conferências, alocuções, sermões e outras obras da mesma natureza; as obras dramáticas e dramático-musicais; as obras coreográficas e pantomímica, dentre outros.

Vê-se que os direitos autorais também são garantidos no ciberespaço, cabendo aos profissionais, elaborar instrumentos normativos que assegurem a efetivação desses direitos. Além disso, esses profissionais devem estabelecer ações voltadas para a educação e conscientização dos usuários quanto ao respeito a esses direitos. É importante refletir que, o controle não deve impedir o acesso, uma vez que, na internetamplia-se o espaço para a efetivação dos direitos constitucionais da liberdade de expressão e informação, pois se permite a livre emissão do pensamento, de forma célere, transpondo barreiras temporais e territoriais (OLIVEIRA; SANTOS; RODEGHERI, 2013). 
De acordo com a Lei Maior da nação, o acesso à informação representa um dos direitos e garantias fundamentais do cidadão, desde que esse acesso seja realizado de forma lícita, sem infringir normas previamente estabelecidas, garantindo direitos de propriedade intelectual sobre as origens das informações (BRASIL, 1988).

A partir do exposto, entende-se que os profissionais que atuam na indústria editorial eletrônica, sobretudo os bibliotecários devem ser catalisadores e disseminadores da informação, bem simbólico e elemento chave na conquista da cidadania, mas também educadores, pois a biblioteca e demais instituições de informação constituem um locus privilegiado do debate, esferas de discussão política e ambientes responsáveis pela democratização da informação (MORIGI; VANS; GALDINO, 2002).

Visando conhecer as maiores dificuldades dos usuários da informação eletrônica, suas percepções e indicações de melhoria, os pesquisadores foram indagados sobre o que consideravam como maiores obstáculos, facilidades e sugestões a serem implementadas, tendo em vista, garantir facilidade do uso das ferramentas, efetividade no processo de busca e legitimidade na utilização das fontes.

"O maior obstáculo que me afeta é encontrar muitos links desativados, documentos que não abrem e também documentos que não estão disponíveis para download [...]. Acho bom a capacidade de navegarmos de um local para outro, ao mesmo tempo [....] Seria bom tornar os sites mais agradáveis, com figuras e letras mas destacadas [...]" (Entrevistado A).

“[...] Tenho dificuldade em acessar certas bases de dados que pedem cadastro, número de senha, e às vezes esse acesso somente é permitido enquanto estamos nas dependências da universidade [...]. Sugiro que essas dificuldades de acesso fossem mais facilitadas [...]" (Entrevistado B).

"[...] Acho fantástico algumas estratégias de busca criadas, bem como os indicadores de citações, [...] Tenho algumas dificuldades em utilizar todas essas possibilidades [...] $\mathrm{O}$ acesso muitas vezes é restrito a certos locais [...] Como melhoria, sugiro a realização de treinamentos, disponibilização de tutorias no site, divulgação dos treinamentos [...]" (Entrevistado C).

Sobre essas questões acima apresentadas, os profissionais foram indagados a respeito do que tentam fazer para reduzir as problemáticas geradas com o uso intensificado da informação eletrônica, tornando essas práticas cada dia mais utilizáveis, democráticas e seguras.

“[...] Os problemas são grandes. As dúvidas também. É preciso participação da universidade e do poder público no sentido de adotar ações voltadas para a resolução dessas problemáticas [...] Entendo que a educação do usuário é a principal estratégia para atingir o sucesso, pois percebemos que muitos produtos e serviços oferecidos não são utilizados [...] Realizamos poucos estudos de usuários e poucos treinamentos com essa especificidade [...]" (Entrevistado D).

“[...] Imagino que a questão da comodidade oferecida nas interfaces dos periódicos certamente é um fator determinante na satisfação dos leitores [...] Aqui, nós temos apoio de profissionais para tornar o site mais atrativo [...] Mas, é preciso firmar outras parcerias, especialmente com bibliotecários [...] A questão legal que envolve o uso da informação seria melhor controlada se fossem melhores divulgadas na sociedade, as questões legais [...] (Entrevistado E). 
A respeito do que consideram os pesquisadores entrevistados, discute-se, com grande frequência na literatura, como a arquitetura informacional interfere na visibilidade. De acordo com Gruszynski e Golin (2007), é preciso utilizar novos formatos de disponibilização de metadados e práticas de representação mais consistentes. De modo geral, é prioritário sintonizar as informações disponíveis, tornar a mensagem única e assegurar a credibilidade do que está sendo comunicado.

No que se refere às problemáticas relacionadas a direitos autorais e demais licenças, não resta dúvida de que a educação pode representar uma estratégia viável, com vistas a consolidar a formação consciente no uso da informação. Sobre a capacitação do usuário, através de práticas educativas como os treinamentos, o papel de bibliotecário-educador será tanto na instrução formal para o uso das tecnologias de informação quanto no planejamento de softwares interativos, ou outras formas de comunicação para o acesso à informação (CUENCA, 1999).

Dentre os vários benefícios que a educação/capacitação do usuário pode representar, destaque especial pode ser atribuído ao desenvolvimento de buscas na sua área, na seleção e localização da informação, no conhecimento das várias formas de acesso à informação e ao documento, e, por fim, a tentativa de manter o usuário constantemente atualizado nessas tecnologias e formas de acesso (CUENCA et al., 1999). 


\section{RESULTADOS PARCIAIS/FINAIS}

Seguindo os objetivos propostos na condução desta pesquisa, e após apresentação e discussão dos dados coletados, é possível obter alguns resultados parciais, com base na realidade analisada e tendo as duas categorias de sujeitos investigados, pesquisadores e profissionais da informação. Abaixo estão elencados os resultados alcançados:

- a produção científica na atualidade é viabilizada por meio do uso de fontes disponibilizadas em ambiente virtual; os pesquisadores analisados utilizam essas fontes com mais intensidade do que materiais impressos encontrados nos acervos de bibliotecas;

- os pesquisadores entrevistados enfrentam muitos obstáculos ao fazerem uso das informações eletrônicas, sendo os principais: problemas de estruturação dos instrumentos de busca, fontes desativadas, conteúdo parcial das informações, não reconhecimento de licenças e direitos autorais e a utilização de informações não confiáveis e inseguras;

- como vantagens principais no acesso à informação eletrônica os pesquisadores reconhecem: a criação de instrumentos facilitadores na busca e recuperação da informação, a utilização dos OPACs, a rapidez de localização e compartilhamento da informação, interatividade e o acesso a publicações recentes. Como melhorias, sugerem a reestruturação da arquitetura informacional e a realização de treinamentos a fim de capacitá-los quanto ao acesso e uso da informação no ambiente digital;

- os profissionais destacam o valor que as informações eletrônicas podem proporcionar à produção científica, porém enfatizam problemas relacionados aos direitos autorais.

- os profissionais sinalizam como possibilidades de solução, o trabalho colaborativo e interdisciplinar entre diferentes áreas, assim como o engajamento e valorização por parte da universidade e do poder público em formular ações voltadas para a educação da população, tornando-a capacitada a usufruir das inúmeras possibilidades oriundas com o uso do ambiente digital.

- A educação do usuário viabilizada pela prática do treinamento torna-se uma estratégia de duplo benefício pois, além de capacitar o usuário quanto ao uso dos novos artefatos tecnológicos, também torna-o ciente quanto ao uso lícito de licenças e direitos relativos à propriedade intelectual e editorial. 


\section{CONSIDERAÇÕES PARCIAIS/FINAIS}

Com base nas discussões propostas e apresentadas neste estudo, constatou-se que o acesso às informações eletrônicas, potencializado com a origem da internet, produziu inúmeros impactos em toda a ambiência que perpassa a produção científica e a indústria editorial. Este fato desencadeia a necessidade de reestruturar todo 0 processo de comunicação científica, envolvendo novas práticas a serem utilizadas por pesquisadores, editores e profissionais da informação.

O paradigma da disseminação da informação, fortemente instituído na sociedade contemporânea, aliado à consolidação do ciberespaço, remete-se ao movimento do acesso aberto. Embora desperte inúmeras vantagens, esse movimento requer 0 estabelecimento de padrões normativos a fim de evitar práticas ilícitas por parte dos usuários no uso da informação, além de condicionar um novo espaço de trabalho para os profissionais envolvidos com a transferência da informação.

$\mathrm{O}$ estudo constatou, com base em entrevista aplicada a pesquisadores e profissionais da informação de uma universidade, que o novo espaço de comunicação científica proporciona inúmeras vantagens, sobretudo àquelas relacionadas à localização e compartilhamento da informação, sem limitações de tempo e de espaço. No entanto, também destacam-se alguns impactos, especialmente às complexidades dos objetos digitais e sua disponibilização em repositórios e bases de dados, no intuito de garantir segurança e legalidade quanto ao uso desses objetos sem provocar infrações à legislação vigente sobre direitos autorais e editoriais.

Com base neste estudo, conclui-se que é preciso estabelecer políticas de acesso a esses ambientes, bem como a divulgação de como utilizar os documentos sem impactar com problemas de direitos autorais. Também, constatou-se, tanto por parte dos pesquisadores quanto profissionais, a necessidade de capacitar o usuário da informação eletrônica, tendo em vista sua adequação aos limites impostos pelo ambiente virtual.

As discussões relacionadas ao uso da informação em acesso aberto trazem à baila inúmeros aspectos relevantes, despertando a necessidade da elaboração de novos estudos que indiquem soluções para tornar essas práticas mais seguras e lícitas, condicionando a democratização da informação, com vistas à garantia de direitos e deveres de todos os cidadãos inseridos na sociedade da informação.

Assim, recomenda-se a realização de pesquisas junto a profissionais especializados em tecnologia da informação, a fim de elaborar novos instrumentos, com vistas a garantir melhor representação e recuperação da informação. Também constatou-se a necessidade de estudos interdisciplinares com profissionais do Direito, tendo em vista elaborar medidas normativas que assegure o respeito à propriedade intelectual e editorial, garantindo a concretização dos direitos e deveres de todos os envolvidos no mercado da informação. 


\section{REFERÊNCIAS BIBLIOGRÁFICAS}

BRASIL. Constituição da República Federativa do Brasil (1988). Brasília: Senado Federal, 1988.

. Lei $\mathbf{n}^{\circ} \mathbf{9 . 6 1 0}$, de 19 de fevereiro de 1998. Altera, atualiza e consolida a legislação sobre direitos autorais e dá outras providências. Disponível em: < http://www.planalto.gov.br/ccivil 03/leis/19610.htm>. Acesso em: 5 ago. 2014.

CASTELLS, Manuel. A sociedade em rede. 10. ed. rev. ampl. São Paulo: Paz e Terra, 2007.

CUENCA, Angela Maria Belloni. O usuário final da busca informatizada: avaliação da capacitação no acesso a bases de dados em biblioteca acadêmica. Ci. Inf., Brasília, v. 28, n. 3, p. 293-301, set./dez. 1999. Disponível em: < http://www.scielo.br/pdf/ci/v28n3/v28n3a7.pdf>. Acesso em: 6 ago. 2014.

; et al. Capacitação no uso das bases Medline e Lilacs: avaliação de conteúdo, estrutura e metodologia. Ci. Inf., Brasília, v. 28, n. 3, p. 340-346, set./dez. 1999.

Disponível em: < http://www.scielo.br/pdf/ci/v28n3/v28n3a12.pdf>. Acesso em: 5 ago. 2014.

DELEUZE, Gilles; GUATTARI, Félix. Mil platôs: capitalismo e esquizofrenia. Rio de janeiro: Ed. 34, 1995.

FERRARI, Rodrigo Duarte; PIRES, Giovani De Lorenzi. Auto-arquivamento e acesso aberto: deveres e direitos digitais na sociedade de rede. Rev. digit. bibliotecon. cienc. inf. Campinas, SP, v. 12, n. 1, p. 22-38, jan./abr. 2014. Disponível em: < http://www.sbu.unicamp.br/seer/ojs/index.php/rbci/article/view/3874/pdf 48>. Acesso em: 5 ago. 2014.

FREITAS, Marilia Augusta; MAIA, Luanna Cezar; LEITE, Fernando César Lima. Acesso aberto como estratégia de disseminação e preservação da produção científica discente: a Biblioteca Digital de Monografias da Universidade de Brasília. Bibl. Univ., Belo Horizonte, v. 1, n. 1, p. 71-80, jan./jun. 2011. Disponível em: <file:///C:/Users/Guest/Downloads/24-170-1-PB.pdf>. Acesso em: 5 ago. 2014.

GIL, Antonio Carlos. Entrevista. In: ed. São Paulo: Atlas, 1999. Cap. 11, p.117-127.

Métodos e Técnicas de Pesquisa Social. 5. . Como elaborar projetos de pesquisa. 5. ed. São Paulo: Atlas, 2010. 
GRUSZYNSKI, Ana Cláudia; GOLIN, Cida. Periódicos científicos eletrônicos e a visibilidade da ciência na web: estudo de caso na UFRGS. DataGramaZero. Rio de Janeiro, v. 8, n 3, jun. 2007. Disponível em:<http://www.dgz.org.br/jun07/Art 02.htm>. Acesso em: 6 ago. 2014.

KURAMOTO, Hélio. Prefácio. In: LEITE, Fernando César Lima. Como gerenciar e ampliar a visibilidade da informação científica brasileira: repositórios institucionais de acesso aberto. Brasília: IBICT, 2009, p. 7-10.

LEITE, Fernando César Lima. Como gerenciar e ampliar a visibilidade da informação científica brasileira: repositórios institucionais de acesso aberto. Brasília: IBICT, 2009.

LÉVY, Pierre. Cibercultura. São Paulo: Editora 34, 1999.

MOREGI, Valdir José; VANZ, Samile Andréa de Souza; GALDINO, Karina. O bibliotecário e suas práticas na construção da cidadania. Revista ACB, Vol. 7, No 2, 2002. Disponível em: http://revista.acbsc.org.br/index.php/racb/article/viewArti cle/390/479. Acesso em: 5 de ago. 2014.

MUELLER, Suzana Pinheiro Machado. A ciência, o sistema de comunicação científica e a literatura científica. In: CAMPELLO, Bernadete Santos; CENDÓN, Beatriz Valadares; KREMER, Jeannette Marguerite. Fontes de informação para pesquisadores e profissionais. Belo Horizonte: Ed. UFMG, 2000, p. 21-34.

. A comunicação científica e o movimento de acesso livre ao conhecimento. Ci. Inf., Brasília, v. 35, n. 2, p. 27-38, maio/ago. 2006. Disponível em: < http://www.scielo.br/pdf/ci/v35n2/a04v35n2.pdf>. Acesso em: 5 ago. 2014.

OLIVEIRA, Carla Cristina Vieira de. A interação de usuários da UFMG com o catálogoon-line do sistema do Pergamum . Revista Brasileira de Biblioteconomia e Documentação, São Paulo, v. 4, n. 2, p. 73-88, jul./dez. 2008. Disponível em: http://www.febab.org.br/rbbd/ojs-2. 1.1/index.php/rbbd/article/viewFile/104/144. Acesso em: 5 ago. 2014.

OLIVEIRA, Flasleandro Vieira Oliveira; GOMES, Sandra Lúcia Rebel Gomes. A licença Creative Commons e o movimento de acesso aberto à informação científica: um olhar para a Scientific Electronic Library on Line (SciELO). In: CONGRESSO BRASILEIRO DE BIBLIOTECONOMIA, DOCUMENTAÇÃO E CIÊNCIA DA INFORMAÇÃO, 25., 2013, Florianópolis. Anais eletrônicos... Florianópolis: FEBAB, 2013. p. 1-16. Disponível em: <file:///C:/Users/aluno-ccje/Desktop/1602-1615-1-PB.pdf>. Acesso em: 2 out. 2014. 
OLIVEIRA, Rafael Santos de Oliveira; SANTOS, Noemi de Freitas; RODEGHERI, Letícia Bodanese. Judicialização de conflitos no ciberespaço: desafios à liberdade de expressão na blogosfera. Revista de Direitos Fundamentais e Democracia, Curitiba, v. 13, n. 13, p. 160-178, jan./jun. 2013.

PACKER, Abel Laerte. A construção coletiva da Biblioteca Virtual em Saúde. Interface, v.9, n.17, p.249-72, mar./ago. 2005. Disponível em: $<$ http://www.scielo.br/pdf/icse/v9n17/v9n17a04.pdf>. Acesso em: 5 ago. 2014.

SANTA ANNA, Jorge. A (r)evolução digital e os dilemas para a catalogação: os cibertecários em atuação. In:ENCONTRO INTERNACIONAL DE CATALOGADORES, 9; ENCONTRO NACIONAL DE CATALOGADORES, 2, Anais Eletrônicos. Rio de Janeiro: Biblioteca Nacional, 2013. Disponível em: < file:///C:/Users/aluno-ccje/Downloads/21185-1-PB\%20(2).pdf>. Acesso em: 15 abr. 2014.

WEITZEL. S. R. O papel dos repositórios institucionais e temáticos na estrutura da produção científica. Em Questão, v. 12, n. 1, p. 51-71, 2006. Disponível em: <http: //eprints. rclis. org/12101/1/ weitzel_repositorios. pdf>. Acesso em: 5 ago. 2014. 


\section{APÊNDICE A - ROTEIRO DE PERGUNTAS PARA ENTREVISTA}

\section{PERGUNTAS DIRECIONADAS AOS PESQUISADORES}

1 - Ao realizarem suas pesquisas, em quais locais vocês mais recorrem? Quais fontes de informação vocês mais utilizam? Utilizam as fontes de pesquisa disponibilizadas na internet?

2 - Vocês possuem conhecimento necessário para utilizar as potencialidades oferecidas pelas novas tecnologias? Sabem selecionar as informações confiáveis e disponibilizadas para uso? Conhecem as leis que regem a utilização/acesso das informações eletrônicas?

3 - O que vocês consideravam como maiores obstáculos, facilidades e sugestões a serem implementadas, tendo em vista, garantir facilidade do uso das ferramentas, efetividade no processo de busca e legitimidade na utilização das fontes eletrônicas?

\section{PERGUNTAS DIRECIONADAS AO BIBLIOTECÁRIO E EDITOR}

1 - Quais os impactos que o uso das fontes eletrônicas vem desencadeando, sobretudo ao trabalho dos profissionais atuantes no mercado da indústria editorial?

2 - No entendimento de vocês, o que pode ser feito para que as informações disponibilizadas no ambiente digital sejam mais acessíveis para o usuário, tendo em vista a disseminação da informação?

3 - O que vocês tentam fazer para reduzir as problemáticas geradas com o uso intensificado da informação eletrônica, tornando essas práticas cada dia mais utilizáveis, democráticas e seguras? 